\title{
DOS PIRAS FUNERARIAS BARROCAS *
}

\section{Elisa Vargas Lugo}

En 1946 Francisco de la Maza publicó un interesante estudio sobre piras tunerarias ${ }^{1}$ en el que dejó registradas treinta y seis obras; desde la primera pira erigida con motivo de la falsa noticia de la muerte de Hernán Cortés, hasta una -de intención burlona- dedicada al cadáver de una perrita, en 1799. Sin considerar esta última, entre las piras estudiadas por De la Maza, se cuentan: trece dedicadas a la realeza española; siete a altos dignatarios de la Iglesia novohispana; cuatro para autoridades civiles; una para el aristócrata queretano Marqués de la Villa del Villar del Águila y una para un heroico grupo de soldados.

Las piras objeto de este estudio, fueron hechas para otro tipo de personas. La primera de ellas fue una pira de uso común y la segunda fue creada para José de la Borda, minero rico que nunca tuvo ni cargos públicos ni títulos nobiliarios. Ambas fueron consignadas desde hace algunos años, pero no se hicieron estudios completos de ellas ni se estableció su categoría dentro de los diferentes tipos de piras. ${ }^{2}$

El empleo de monumentos funerarios fue extensivo a todas las clases sociales. La diferencia radicaba en que las piras propiamente dichas -o sean aquellos monumentos profusamente iluminados- estaban destinados a las clases altas, y para los pobres se usaban túmulos muy sencillos pintados de negro solamente; algunas veces éstos tuvieron formas de simples ataúdes y otras podían tener varios cuerpos escalonados pero sin ornamentación, aunque sí con algunas velas. Ejemplos de estos sencillos monumentos han llegado a nuestros días en varias pinturas. Tres de ellas merecen especial mención: las que se conservan en los templos de Huejotzingo y de Quecholac, en Puebla, y la de la iglesia de Yauhquemecan, en Tlaxcala. ${ }^{3}$

* Este axtículo fue presentado como colaboración en el Simposio sobre Arte Funetario organizado por el Comité Mexicano de Historia del Arte en el mes de octubre de 1980, en la ciudad de México.

1 Francisco de la Maza, Las piras funerarias en la historia y en el arte de México, México, 1946.

2 Cfr. Manuel Toussaint, Tasco, México, Publicaciones de la Secretaria de Hacienda, Editorial Cultura, 1931, p. 96; Pál Kelemen "A mexican colonial Catafalque", The Art Quarterly, vol, xxviI, núm. 4, 1965 y Art of the Americas, New York, Bonanza Books, 1969, p. 277.

3 Cfr. Jesús Franco, "Una pintura de ánimas en San Dionisio Yauhquemecan Tlaxcala", Anales, núm. 47, México, UNAM, 1977, p 117. 
Francisco de la Maza informa en la introducción de su citado estudio sobre las piras mexicanas que, cuando éstas eran de excelente estructura se conservaban para ser usadas en varias ocasiones, "como se verá después - dice- en la que hizo Tolsá para el arzobispo Lizana, o en el caso del poeta José Manuel Sartorio, en 1829, en la iglesia de la Santa Veracruz, para cuyas honras fúnebres se consiguió la muy preciosa y alabada pira de los ciudadanos socios de San Pablo, cuya arquitectura no se describe porque es muy conocida en esta ciudad". ${ }^{4}$

Empero estas piras que menciona De la Maza pertenecieron ya al estilo neoclásico, así que -casi seguramente- por sus lineamientos sobrios pudieron haberse prestado para ser usadas varias veces. En cambio las monumentales piras barrocas, tan llenas de emblemas, versos, tarjas y demás elementos, alusivos unos y representativos otros, de las personas de las clases altas y dirigentes para quienes fueron erigidas, difícilmente servirían más de una vez.

Sin embargo, por otra parte, creo que sí existieron piras de categoría formal y social intermedia, para uso de la comunidad, pero obviamente con temas generales en su iconografía y menos esplendorosamente iluminadas que las que se creaban para las exequias de las autoridades y clases priviligiadas.

\section{Una pira para la clase media}

Pira para uso común fue -tal como lo demuestra su iconografía- el túmulo dieciochesco perteneciente a la Orden carmelita de la ciudad de Toluca. Fue el especialista Pál Keleman quien dio a conocer esta interesante obra en un artículo que le dedicó en 1965 -ya citado-, en el que hace descripción de todos los paneles y analiza el significado de algunos de los símbolos y composiciones de acuerdo con las Sagradas Escrituras y las tradiciones católicas. Por tanto, los comentarios que aquí se hacen sobre esta pira, pretenden más que nada valorar su iconología para catalogarla dentro de este rico tipo de expresiones barrocas necrológicas.

La pira tuvo cuatro cuerpos, pintados al óleo -con una altura aproximada de $3.24 \mathrm{~m}$-y seguramente un remate, ya desaparecido, que la hacía más elevada. En cada panel la representación se acompaña con tarjas que contienen versos en castellano y con filacterias con inscripciones latinas.

4 Francisco de la Maza, op. cit., p. 15. 
En resumen, en el primer cuerpo se representa la muerte de las cuatro jerarquías más importantes en el mundo católico de la época: el rey, el pontífice, el cardenal y el obispo; en el segundo nivel, el amor, la juventud y la riqueza se ven por igual atacados por la muerte, y se dejó escrito que todos "... en montón de muertos velarán". En la tercera sección las representaciones de los páneles se refieren a la Muerte en relación con el Tiempo y la Resurrección. En el cuarto y último nivel en donde queda sólo uno de los cuatro lienzos que lo formaron, se representa el momento en que Sansón tomaba la miel del hocico del león de Timna. Seguramente en los tres lienzos perdidos estuvieron representadas las otras tres hazañas de Sansón, o sea, cuando mató a los filisteos con la quijada de burro, cuando fue engañado por Dalila y cuando ciego, en Gaza, derribó la casa en donde estaban los príncipes filisteos. ${ }^{5} \mathrm{La}$ presencia de Sansón en esta pira debe entenderse -tal como la tradición católica señala y ya lo anotó Kelemen $-{ }^{6}$ como prefiguración de Cristo salvador de la humanidad, y sus valerosas hazañas como la lucha de Cristo y su triunfo contra el Mal.

Se insiste por supuesto, mediante varias escenas, en el carácter inelu dible de la Muerte, y entre tales representaciones destaca la del Carro de la Muerte; ésta se ve en forma de esqueleto, sentada y coronada con laureles en señal de victoria. Dicho sea de paso la representación de este carro es un ingenuo y abreviado remedo de los grandes carros de triunfo rubenianos que tanto se representaron en la pintura novohispana. Va tirado por un león y un águila, en actitud temerosa, que representan, en este caso, los valores del mundo terreno y del mundo espiritual, respectivamente y que en cualquier momento pueden ser aniquilados por la Muerte.

La riqueza y posición social están representadas en la misma escena por una pareja de personas muy bien vestidas, que va atada con cadenas al carro de la Muerte sobre el cual se ven objetos que representan los poderes eclesiásticos y civiles. Con todo ello se quiso expresar, tal como lo dicen los versos de la octava que complementa la escena: [La Muerte] "... de todos triunfa y en su carro abarca, cuantos despojos le quitó a la vida, por eso ostenta ceptros, y bastones, tiaras, capelos, mitras y pendones." Existe una representación de una doncella herida instantáneamente por la Muerte. El mote dice: "Muere de repente herida."

5 Jueces, xinI a xvi.

6 Pál Kelem, Art of the Americas, p. 278. 
Clara alusión a la posibilidad de que una muerte repentina puede atacar a la juventud. $\mathrm{Y}$ así, en otros paneles, se ejemplifican las victorias de la Muerte sobre la belleza, el amor, la vida religiosa, etcétera. Una graciosa figura de ángel-Mercurio, personaliza al Tiempo en su lucha contra la Muerte, quien sin apresurarse camina, vencedora, delante de él. Pero en medio de tantas muestras del poder absoluto de la Muerte, en la escena en que aparece un hombre joven ante la Muerte -en el tercer nivel de la pira se introduce un elemento más de advertencia, pero a la vez de esperanza porque simboliza el Juicio Final y la Resurrección. Es éste la trompeta que aparece cerca de la oreja del personaje y que se complementa con el mote latino: Inictu oculi in novissima tuba, que significa: "A un guiño del ojo, en la última [llamada] de la trompeta." Seguramente se esperaba con esta frase y con esta escena, despertar en el doliente público -que se suponía debidamente instruido en su religión- la imagen de la salvación del alma, ya que dichas palabras derivan de la Primera Epistola de san Pablo a los Corintios y se refieren precisamente a la Resurrección. El texto del santo, dice:

En un instante en un abrir y cerrar de ojos, al último toque de la trompeta - pues tocará la trompeta- los muertos resucitarán incorruptos y nosotros seremos inmutados. Por que es preciso que lo incorruptible se revista de incorrupción y que este ser mortal se revista de inmortalidad. Entonces se cumplirá lo que está escrito: la Muerte ha sido sorbida por la Victoria. ${ }^{7}$

Este significativo panel, parece ser el enlace iconológico más directo con el cuerpo superior, en donde se ve a Sansón con el león de Timna que, como ya se dijo y es del conocimiento general, significa el triunfo de Dios sobre el Mal. Por tanto, la posibilidad de la salvación del alma quedó así expresada con claridad y certeza mediante la recia alegoría de Sansón, en la parte más alta de la pira, lo cual tampoco es casual, como se comprenderá No cabe duda que el autor intelectual de esta obra tenía en la mente estas otras frases de san Pablo: "DDónde está, Muerte, tu victoria?” "¿Dónde está, Muerte, tu aguijón?" Es decir que si bien mediante la iconografía de las piras funerarias se quería ejemplificar, impresionar y hasta amedrentar a los fieles, es evidente que era también parte esencial del programa el final triunfalista del Bien sobre el Mal, del Espíritu sobre la Muerte y así de la salvación del alma. Para

7 San Pablo, Epistola a los Corintios, xv, 52 a 55. 
completar la lectura del mensaje Muerte-salvación, que trasciende toda la composición, se dio especial importancia a la figura del peregrino -que aparece en dos o tres escenas-, claro está, con el sentido bíblico de que ". todos somos peregrinos sobre la Tierra; que vivimos en esta vida terrenal en camino hacia la eterna" 8 y que por lo tanto debemos estar justamente preparados siempre a bien morir.

Pál Kelemen tiene razón al comentar que en esta composición se hace evidente la sabiduría y erudición de los frailes carmelitas sobre este tema, pues ellos, de manera especial y constante, meditaban sobre la muerte. ${ }^{9}$ Al respecto debe añadirse que tal erudición fue hábilmente manejada por el autor para que el programa iconográfico fuera, con relativa rapidez, fácilmente asimilado por un público medio y numeroso.

Si se toman pues en cuenta, el programa de esta pira y la manera tan clara de representar las escenas pictóricas, el lenguaje llano de los poemas, el tamaño discreto del túmulo, así como el tipo de personajes que aparecen protagonizando las escenas con -salvo Sansón- trajes de la ćpoca en que fue construida esta pieza - como ya también observó Kelemen- no parece caber duda acerca de que sus funciones estaban desti. nadas a servir, de manera principal, para las exequias de la sociedad acomodada, aunque no aristócrata, de Toluca. Puede ser que hubiera sido posible utilizarla para las honras fúnebres de algún sacerdote o de alguna monja del bajo clero, pero obviamente no resultaba apropiada para celebrar los funerales de eclesiásticos importantes, ni de personajes muy encumbrados, ni de gente humilde.

Con seguridad, sobre las esquinas de cada cuerpo se colocaban velas que iluminaban el conjunto, pero, como se verá adelante, el número de luces estaba reglamentado por una Pragmática real que no ha sido posible localizar y por el momento se desconoce la cantidad de luminosidad que era permitido dar a las piras de este género medio y de uso común.

\section{La pira de Johé de la Borda}

Manuel Toussaint, en su monografía sobre la ciudad de Taxco, publicada en 1931, dio a conocer la Fúnebre Parentación, escrita por José Antonio Ximénez y Frías ${ }^{10}$ a la muerte de José de la Borda y publicó

8 San Pablo, Epistola a los Hebreos, XI, 13.

9 Pál Kelemen, op . cit., p. 278.

10 José Antonio Ximénez y Frías, El Fénix de los mineros ricos de la América. Fúnebre Parentación, México, Imprenta de Felipe Zúñiga y Ontiveros, 1799, s/p. 
un dibujo de la pira funeraria que acompañaba dicho texto (fig. 4) Aprovechó algunos de los datos biográficos de Borda que se mencionan en el discurso del párroco, pero sin ocuparse particularmente de la pira. ${ }^{11}$

La ilustración que de dicha obra acompaña este artículo es reproducción de la que publicó Toussaint.

José de la Borda, el minero más ilustre del siglo xvin en la Nueva España y gran benefactor de la ciudad de Taxco y de sus habitantes, murió el 30 de mayo de 1778 en la ciudad de Cuernavaca, en donde su hijo Manuel era entonces cura párroco. La triste nueva llegó al Real de Minas de Taxco al día siguiente, 31 de mayo. Reunidas con tal motivo varias personalidades de la población con el párroco José Antonio Ximénez y Frías, se decidió escribir de inmediato a don Manuel de la Borda ".. pidiéndole que se sirviese determinar, que el cuerpo de su difunto padre se enterrase en esa parroquial iglesia". ${ }^{12}$ Con tal peti. ción se enviaron esa misma noche dos cartas hacia Cuernavaca; una por parte de los seculares y otra por parte de los clérigos. Contra lo que seguramente era de esperarse, Manuel de la Borda contestó con una diplomática negativa. Su xespuesta, fechada el 2 de junio, empieza por dar las gracias por las condolencias recibidas y por el dolor manifestado por el pueblo de Taxco con motivo de la muerte de su padre y se disculpa por no enviar los restos de éste, dando a entender que la petición había llegado demasiado tarde, puesto que

.. cómo me llegó esta amorosa súplica a tiempo de que ya estaba su cuerpo en la parroquial de esta Villa, no había lugar de suspender sus funerales ... a fin de conducir el cadáver a ese Real; y no habiendo en mi facultad para poder trasladarlo a él, sólo queda en V. M. la diligencia de conseguirlo al tiempo determinado, si fuere del agrado de S. S. Illma. ${ }^{13}$

Esta negativa se recibió en Taxco el 3 de junio y debió haber causado gran descontento entre sus habitantes quienes, por lo pronto, desde el día primero de ese mes habían comenzado un Novenario de Misas cantadas, seguido el día 3 por un Rosario de Animas que se efectuaba - "... con muchas luces..."- por las noches, en las calles de la ciudad. Es interesante informar que el dia 13 del mismo mes

11 Manuel Toussaint, op. cit., p. 95-97

12 José Antonio Ximénez y Frías, op. cit.

13 Ibid. 
-según dice Ximénez y Frías- en Tehuilotepec, lugar en donde Borda comenzó a hacer su fortuna, se le preparó un sufragio elevándose para ello ". . . una tumba de cinco cuerpos" en medio de la iglesia, con "... sus correspondientes luces... misa solemne, responsos, etcétera". ${ }^{14}$

En tanto el tiempo corría, y los taxqueños, convencidos ya de que no obtendrian los restos de Borda, decidieron celebrar sin ellos las honras fúnebres el 17 de junio. Pero como se consideró necesario elevar también una tumba o pira -diferente de la de Tehuilotepec-se difirió ia celebración hasta el 27 del mismo. Durante los preparativos llegó a Taxco don Antonio de Villanueva, diputado de la minería, quien no contento con la sencillez de los proyectos para la función luctuosa, propuso que se hicieran en mayor escala, y la fecha hubo de cambiarse una vez más, señalándose el día 26 de agosto, “. . dando con esto tiempo a que se fabricase una magnífica pira encargándome previniese algunas piezas para que la adornasen", afirma Ximénez y Frías. ${ }^{15}$ El mismo personaje informa que, como no había tiempo para recurrir a los artistas de México, ni tampoco había en Taxco quien fuera capaz de esa tarea, tuvo él que hacerlo, y comenta ". . procuré sin faltar a las indispensables y diarias ocupaciones de mi empleo concluir lo más breve dicho adomo para la Pira, entretanto muchos oficiales se ocupaban de la fábrica y pintura del cuerpo de la pieza...", cuya ejecución ayudaba a vigilar don Francisco Miguel Domínguez, ${ }^{16}$ devoto colaborador y hombre de confianza de José de la Borda. Sin embargo, a pesar del gran interés que éste debió de haber puesto, no logró que el trabajo se terminara a tiempo Los oficiales informaron en un momento dado, que la obra no podía estar terminada y armada para el 26 de agosto, a pesar, dice Ximénez y Frías, de que “. . para evitar defectos del pincel en las tarjas, las hice trabajar en mi casa y a mi vista". 17 El sufragio por lo tanto hubo de retrasarse para el 3 de septiembre, pero se celebró con "... una pieza [o sea la pira] verdaderamente magnífica .." dentro de la iglesia parroquial.

14 Ibid

15 Ibid.

16 Ibid. Este personaje fue un gran colaborador y admirador de José de la Borda y quien obsequió los retratos de hombres taxqueños ilustres, que forman la pequeña galería que se conserva en la sala capitular de la parroquia. Cfr. Elisa Vargas Lugo, La iglesia de Santa Prisca de Taxco, México, UNAM, 1974 y 1982 17 Ibid. 
La misa de Requiem se celebró a las diez de la mañana en el altar mayor, seguida de un responso muy solemne. Con capas pluviales negras, aficiaron los R.R.P.P. "Tr. Gabriel Vidaña, Guardián del convento de San Bernardino de este Real, y hoy Definidor de su Provincia de San Diego de México; el R.P. Fr. Juan Guadalupe de León, ex Guardián del mismo Convento; el Sr. don Juan Diego Gutiérrez, Cura por S.M. y Juez Eclesiástico por el pueblo de Cacalotenango, y el Dr. D. Miguel Ruiz de la Motâ, Teniente de Cura del Partido de Iguala, y natural de este Real", ${ }^{18}$ quienes para escuchar la oración fúnebre tomaron asiento frente al altar.

Tuvo la pira de José de la Borda, cuatro cuerpos escalonados y un remate piramidal, tal como puede verse en la fotografía y esquema adjuntos (fig. 5). Medía unos 10 metros de altura y fue colocada, no en el crucero del templo, como generalmente se hacía, sino sobre la nave, en el eje formado por la portada lateral y la capilla de Indios, donde se encuentra el altar de Ánimas, y porque en este lugar el monumento podía ser admirado por sus cuatro costados; en cambio, si se hubiera colocado frente al altar mayor, su costado sur no hubiera sido fácilmente visible para los concurrentes.

Tenía la pira albortantes, uno en cada ochavo de los tres primeros cuerpos, en los que con arreglo .... a la última Real Pragmática de nuestro Soberano ${ }^{1.9}$ perteneciente a funerales, se colocaron doce achas de cuatro pavilos, que con las cuatro de los blandones que ocupaban las cuatro esquinas de la tarima, hacían diez y seis dichas (sic) [debía decir bichas] y por consiguiente sesenta y cuatro luces.

Este número de luces resulta francamente bajo en comparación con la pira del marqués de la Villa del Villar del Águila -quien por sus obras de beneficencia social podría compararse con la personalidad de José de la Borda-, que en 1744 tuvo cerca de 445 luces, y como dejó dicho su orador "... con aquel número de luces que se proporcionó convenientemente, para no oscurecer los aparatos debidos sólo a personas reales". ${ }^{20}$ Según puede deducirse de estos datos, el empleo de luces -magnífico recurso para lograr el impacto numinoso y triunfalista que se persigue con las piras barrocas- parece haberse reglamen-

18 Ibid.

19 Ibid

20 Francisco de la Maza, op. cit. p. 73 
tado durante el reinado de Carlos III ${ }^{21}$ por haber llegado a ser abusivo. También resulta fácil pensar que habiendo sido Borda originalmente un individuo de la clase media, de procedencia desconocida, no se hubiera permitido colocar mayor número de luces en su pira.

Es interesante informar que: "El color de esta pieza era, en lo que hace al fondo, de piedra jaspe, salpicada en parte de vivas llamas, que le hacian parecer toda usa hoguera", ${ }^{22}$ apariencia que desde luego tiene que ver con el programa iconológico que la informó, pero que también recuerda y resume el remoto origen ígneo de estos monumentos, el cual se remonta a la simbología bíblica, por una parte, y a las hogueras paganas, por la otra.

Dado que varias veces - según ha quedado dicho- se pospuso la celebración de las honras fúnebres de José de la Borda, se deduce que el párroco José Jiménez y Frías tuvo tyes meses - del 30 de mayo al 3 de septiembre- para escribir la Fúnebre Parentación; pero en cambio, solamente un mes - del 27 de junio en que el diputado de minería Antonio de Villanueva exigió unas honras más suntuosas, al 3 de septiembre en que estas se celebraron para diseñar y mandar fabricar la pira. Esto podía explicar en parte que el complejo, enjundioso, barroco y sumamente erudito texto de la Oración fúnebre, sea mucho más rico que el aspecto formal de la pira, que simplifica los temas tratados en la Oración y es un tanto repetitiva, como puede darse cuenta el lector, por las escenas que se describen en el esquema. Sin embargo, las dos obras forman un todo inseparable Es obvio que del texto de la Fúnebre Parentación se originó la iconografía de la pira, y que posiblemente por falta de tiempo no fue más compleja.

Ambas obras están estructuradas bajo tres directrices: imágenes moralizantes, expresadas por medio de las más reconocidas virtudes de José de la Borda; fundamentación biblica, hecha mediante la reiterada com. paración entre el ilustre minero y el José bíblico, hijo de Jacob y de Raquel, tema que por cierto no aparece representado plásticamente y el gran tema alegórico que lo une todo: el triunfo de los valores espirituales sobre la Muerte, expresado a través de la antigua figura del Ave Fénix.

Tal como puede verse en el esquema, el primer nivel de la pira fue dedicado a representar la autogestación e inmortalidad del Ave Fénix,

21 José Antonio Ximénez y Frías, op. cit.

22 Ibid. 
y los otros tres niveles -aparentemente sin ningún orden especialtanto históricos como alegónicos mostraban escenas en las que Borda era el sujeto principal (fig. 6) . En las alegorías que ornamentaban el segundo nivel debe destacarse la número 8 en la que aparecía el Fénix en una hoguera que encendía el sol y Borda en otra encendida por la Caridad. La descripción de la pira dice que de la boca de Borda salían estas palabras dirigidas al Fénix: Fam sumus ergo pares. ${ }^{23}$ En las tarjas del tercer nivel se podían ver grandes hechos de la vida del minero; las escenas más importantes exan la número 9 en la que se manifestaba que mediante la construcción de la parroquia de Santa Prisca, Borda había logrado la salvación de su alma, y la número 12 que se refería a la hambruna que sufrió la población en 1753 y que él procuró remediar con gran generosidad. En el cuarto nivel se destacó su devoción mariana en la tarja número 13, y la representación de más importancia para la población de Taxco, en ese momento, fue la tarja 14, en la que se veía al difunto en su sepulcro de Cuernavaca, desde donde dirigía a los taxqueños esta frase: Asportate ossa mea vobiscum. ${ }^{24}$ A media altura de la pirámide que remataba el conjunto se colocó una filacieria o rotulón que decía: Et vivat Phoenix unica semper avis. ${ }^{2 \breve{s}}$ Sobre dicha pirámide, dominando todo el conjunto, se veía triunfante, bello e inmortal, al Fénix, sobre un nido en llamas. ,

Por medio de la pureza, la castidad y lá caridad se mostró la ejemplaridad que dio Borda al mundo, pero por medio de la caridad -virtud teologal y "suma de todas las virtudes"- se exaltó de manera superlativa su personalidad moral. Es evidente que por medio de la correlación Caridad-Borda, Ximénez y Frías quiso expresar la imagen del católico perfecto, que vivió apegado al Evangelio: practicando con sus obras la caridad y viviéndola como la suprema ley de la vida "amando al prójimo como a él mismo y a Dios sobre todas las cosas".

Esta brillante imagen se hizo aún más resplandeciente para el público que asistió a las honras fúnebres, al escuchar la palabra Héroe, que a lo largo de la Fúnebre Parentación fue aplicada sistemáticamente sinnúmero de veces, con una intención que parece rebasar la acepción de "varón ilustre y famoso" (que además de la acepción clásica, registra el diccionario de la lengua castellana) para intentar comunicar -a

\footnotetext{
23. "Ya somos por lo tanto pares o iguales"; es decir "inmortales".

24 "I ranspor tad mis huesos con vosotros".

25 "Y viva el Fénix, ave siempre única".
} 
mi juicio- a tal héroe una categoría muy próxima a la santidad. Posiblemente para Ximénez y Frías, así como para muchos taxqueños de su tiempo, José de la Borda fue un santo, o casi un santo, pero no teniendo derecho a aplicar tal calificativo al difunto, el párroco empleó la palabra héroe para ilustrar de alguna manera el espíritu sobrehumano que él y muchos, teconocian en las hazañas piadosas del minero.

Por lo que respecta a la hábil comparación que se estableció entre José de la Borda y José el de la Biblia -considerado por la Iglesia como prefiguración de Cristo- nos dice Ximénez y Frías:

En la última tarja [marcada con el número 16] de este cuerpo se quiso dar un compendio de toda la vida de nuestro Héroe, que fue ciertamente muy parecida en algunos pasajes a la del antiguo Joseph, como se verá en la Oración; por lo que, como aquél, se llama, singular, raro y Fénix de su siglo, ha parecido regular aplicar este elogio al nuestro; ${ }^{26}$

lineas que explican la fuente de inspiración que tuvo el sacerdote para haber seleccionado la alegoría del Ave Fénix y aplicarla en la elaboración de su empresa funeraria. Efectivamente existen varias semejanzas en la vida de los citados personajes que tacilitaron la brillante confección de su sermón:

El nacimiento humilde de ambos; la edad de dieciséis años en que ambos salieron de su lugar de origen; su triunfo en tierras extrañas en donde obtuvieron riqueza, poder y el reconocimiento general; sus virtudes: pureza, castidad y caridad; el hecho de haber salvado a sus pueblos de una época de hambre y por haberse convertido en apoyo y modelo de virtudes para sus semejantes. Además, cuando José, el hijo de Jacob -tal como relata el Génesis-, sintió aproximarse la muerte, hizo jurar a los hijos de Israel diciéndoles: "Ciertamente os visitará Dios; estonces, llevad de aquí mis huesos." "2i Muy satisfecho debe de haberse sentido Ximénez y Frías al encontrar que este hecho coincidía con el anhelo -indiscutible- de los taxqueños por enterrar en la parroquia de Santa Prisca los restos de José de la Borda. Por esto en la tarja número 14 hizo representar - como ya se dijo- al propio Borda pidiendo que sus iestos fueran llevados a Taxco; deseo que, por cierto, la socie. dad taxqueña nunca pudo ver cumplido ${ }^{28}$ Además, nuestro autor

26 José Antonio Ximénez y Frías, op. cit.

27 Géneis, L, 25.

28 Cfr. Elisa Vargas Lugo, op. cit., p. 46. 
termina manifestando su deseo - con toda razón- porque los restos de Borda, como los del antiguo José - que fueron depositados en Egipto y después llevados a Canaán-, fuesen visitados en el sepulcro que debería instalarse en la iglesia de Taxco. ${ }^{29}$

Como broche de oro al parangón de los dos Josés, Ximénez y Frías toma prestado para Borda el epitafio ".. que hace el Eclesiástico del antiguo Joseph... ." y que dice:

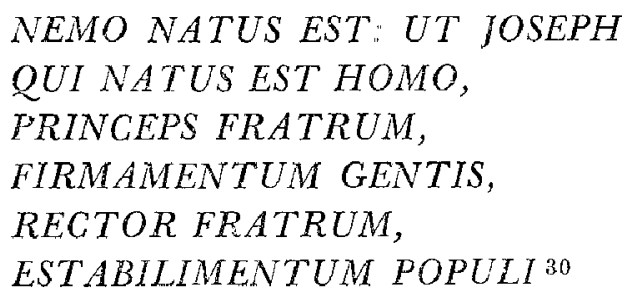

Como simbolismo cristiano, el ave Fénix se introdujo desde el siglo I, cuando san Clemente relató esta leyenda en su Primera Epistola a los Corintios. Su primer significado particular fue el triunfo de la vida eterna sobre la muerte, y posteriormente se convirtió en el símbolo de la Resurrección asociándosele a la Crucifixión. 31 Es interesante señalar que - tal como dice George Ferguson- el ave Fénix se representó mucho durante la Edad Media, pero no así en el Renacimiento, ${ }^{32}$ a lo que hay que añadir que su imagen es también escasa dentro del arte barroco.

Ximénez y Frías, para la elaboración de su Fúnebre Parentación, se inspiró en el bello texto de Claudiano -que forma parte de los capitulos titulados Idilios-, ${ }^{33}$ prosa del siglo iv que parece resumir las informaciones esenciales que, sobre tan prodigiosa criatura habían comunicado varios autores, tales como Herodoto, Ovidio, Tácito, etcétera, desde la más remota antigüedad y que la consideraban un ave solitaria, de singullar hermosura, que lucía parte de su plumaje dorado y las patas crimson.

De los comentarios anteriores se deduce, en resumen, que se quiso

29 José Antonio Ximénez y Frías, op. cit.

30 "Nació nadie: como José que nació hombre, primero de los hermanos, fundamento de la familia, guía de los hermanos, sostén del pueblo."

31 George Ferguson, Signs and Symbols in Chistian Art, Oxford University Press, London, 1977 , p 23.

32 Ibid.

33 Claudien, Oeuvres Complétes, Par's, Librairie Garnier Fréres, traduction nouvelle

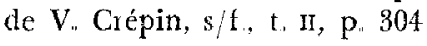


mostray a José de la Borda como el cristiano perfecto, quien por los méritos acumulados gracias a su extraordinario espiritu caritativo, alcanzó -a imagen y semejanza del ave Fénix- el triunfo sobre la muerte, y que como lo demostró el parangón con la vida de Joseph, el personaje bíblico, Borda fue también un elegido de Dios.

A esto hay que añadix además el predominante lugar que se asignó al simbolismo del fuego, mediante el cual se dio intenso énfasis al sentido de inmortalidad, pues como quedó dicho, el fuego se representó envolviendo toda la pira. Si bien es cierto que las piras funerarias barrocas eran creaciones derivadas de las hogueras funerarias paganas, no hay que olvidar la gran riqueza alegórica positiva del fuego, de antiquisima tradición, que se remonta a las primeras etapas de las sociedades humanas y que se encuentra presente también en los textos bíblicos. Para la mayoría de los pueblos primitivos el fuego fue considerado como demiurgo, principio activo del universo, asociado a la vida, a la superioridad, a la energética espiritual, procedente del sol -como el ave Fénix-y triunfador sobre las fuerzas del mal. Los textos bíblicos recogen varios de estos primitivos significados positivos del fuego: como signo de la presencia divina; ${ }^{34}$ como elemento purificador necesario para propiciar los sacrificios ${ }^{35}$ en el altar de los holocaustos y como medio de renovación en el Apocalipsis. ${ }^{36}$ Así pues, suma de todos estos significados acumulados, tuvo para la época barroca la representación del fuego, y sobre todo en el caso de esta pira, es indudable que todos ellos concurrieron a dar el sentido completo del monumento.

El hecho de que se haya exaltado la figura de José de la Borda con fundamento en unos de los más altos niveles alegórico religioso de su tiempo -como el parangón con José, hijo de Jacob-, preconizando por la Iglesia como prefiguración de Cristo, así como la igualdad en la ultravivencia, establecida con el ave Fénix, símbolo de la resurrección y crucifixión -aparentemente nunca antes utilizada en la Nueva España para rendir homenaje a un hombre común- xallanos por otra parte, en la herejía, parecen explicarse por el afán triunfalista inherente y casi obsesivo de la expresividad barroca mexicana de esos siglos. No cabe duda que José de la Borda fue un hombre excepcional, pero de acuerdo a la estricta estratificación social de su tiempo y a la ortodoxia de la fe, resulta exagerado el homenaje, desde el punto de vista precisa

34 Génesis, 15, 17.

35 Levitico, vi, 12-13 e Isaias, 31, 9

36 Apocalipsis xx y xxI 
y puramente religioso que, posiblemente, hubiera sido mal visto de haberse efectuado en la ciudad de México. Es por ello posible pensar que tales libertades de erudición escritural y simbólica pudieron producirse debido al aislamiento en que se vivía entonces en el Real de Minas de Taxco, en el seno de cuya sociedad, tan devota de Borda, nada de lo que se dijo se consideró fuera ni de la realidad, ni de la religión, que para el caso significaban la misma cosa.

Dado que el sentimiento religioso de la época barroca en general, pero de manera especial en la Nueva España, tuvo un sentido casi concreto de los valores espirituales y se distinguió por su decidida inclinación a tratar de unir este mundo con el Más Allá y la fe con la experiencia formal, las piras funerarias barrocas, plásticamente, fueron creaciones que artísticamente pueden hermanarse con la pintura de tipo naturalista - de un naturalismo de muy antigua tradición- presente en las obras no religiosas del arte novohispano, o sean biombos, mamparas, "mapas" de las plazas y calles de las ciudades y "tablas de castas" "En todos estos géneros, los pintores ofrecieron, con diversas calidades, una interpretación más apegada a la realidad, más libre y suelta de las formas humanas y de los ambientes representados. Tal vez por ser las piras obras de arte efímero, no se exigía tan estrictamente el convencionalismo pictórico que privó en la expresión del arte novohispano de primer orden. Es por lo tanto una lástima que tantas piras hayan desaparecido, pues seguramente en sus paneles historiados, deben de haberse recogido incontables e irreconstruibles datos de interés para el conocimiento de la sociedad novohispano. Seguramente hubo muchas diferencias de calidad en las piras. La hecha por Pedro de Arrieta o por algún otro artista de primera importancia deben de haber presentado mayor calidad artística que las pinturas del artista que decoró la pira de Toluca o que las representaciones ejecutadas por los artesanos taxqueños para la pira de Borda, pero en cuanto a intención expresiva, todas deben de haber seguido la misma directriz, concreta y terrena, en la representación de los valores espirituales, impulsados por una necesidad narrativa, muy importante si se toma en cuenta la definitiva preferencia que el arte barroco tuvo por las artes visuales como medios de persuasión.

Cabe aquí dejar asentadas unas líneas de reconocimiento al párroco José Antonio Ximénez y Frías, autor intelectual y asesor en la ejecución de la pira de José de la Borda, tanto por su creación en sí, como 
por los informes que proporciona acerca de cómo deben de haberse elaborado muchas de estas obras de arte efímero.

Como conjuntos plásticos alegóricos, las piras cumplían con tres principales objetivos: exaltar las virtudes y logros espirituales del difunto; aleccionar objetivamente, brindar ejemplaridad a los fieles presentes en las ceremonias, quienes se conmovían a través de la visión óptica del monumento tanto como por las palabras de las oraciones fúnebres; finalmente constituían verdaderos festejos para los sentidos y el espíritu. El triunfalismo religioso que las animaba no escatimaba recurso a su alcance para convertir, barrocamente, a cada uno de estos monumentos en una obra única y -de ser posible- de riqueza superlativa La forma piramidal ascendente que las informaba, sus remates espectaculares, su urnamentación pictórica y literaria y sobre todo las numerosas luces que Las iluminaban producían de manera concreta, palpable y muy barroca un feliz contrapunto al aspecto macabro funesto y negativo de la muerte. Al encenderse cada pira acompañada de brillante liturgia y copiosa wratoria erudita debe de haberse exaltado con júbilo la piedad de los fieles; las exequias así celebradas eran gozosas, eran un espectáculo de gala para la sociedad, eran parte del fausto barroco de aquellos tiempos. Así, el ígneo monumento purificador debe haber producido entre los asistentes la convicción de que efectivamente ". . . la muerte fue sorbida por la Victoria", como dijera san Pablo. 
DOI: http://dx.doi.org/10.22201/iie.18703062e.1983.53.1210 
DOI: http://dx.doi.org/10.22201/iie.18703062e.1983.53.1210

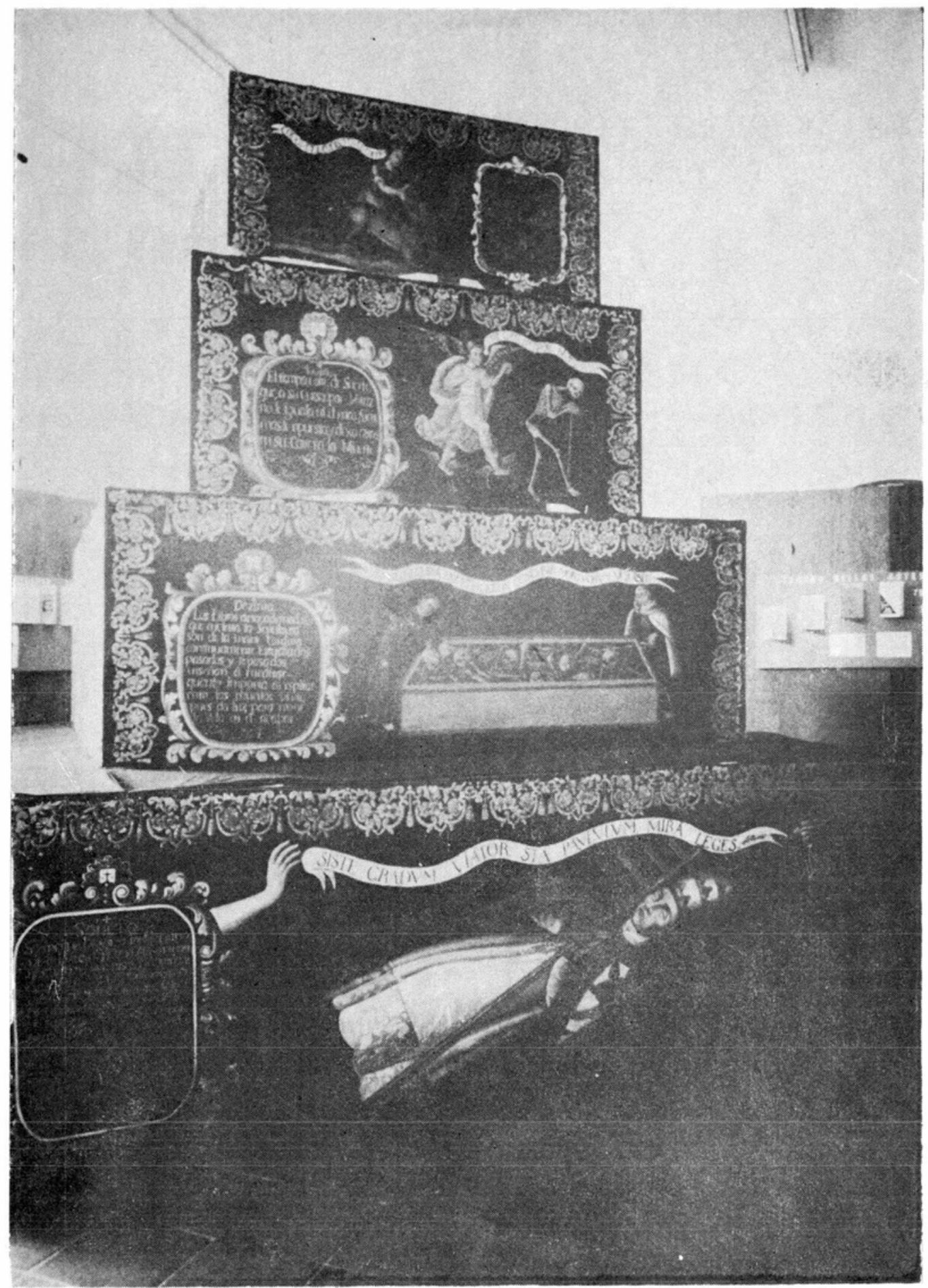

Figura 1. Pira que perteneció al convento de frailes carmelitas de la ciudad de Toluca. Siglo XVIII. Actualmente se conserva en el Museo de Bellas Artes de dicha ciudad. Foto: Rafael Rivera. 
DOI: http://dx.doi.org/10.22201/iie.18703062e.1983.53.1210

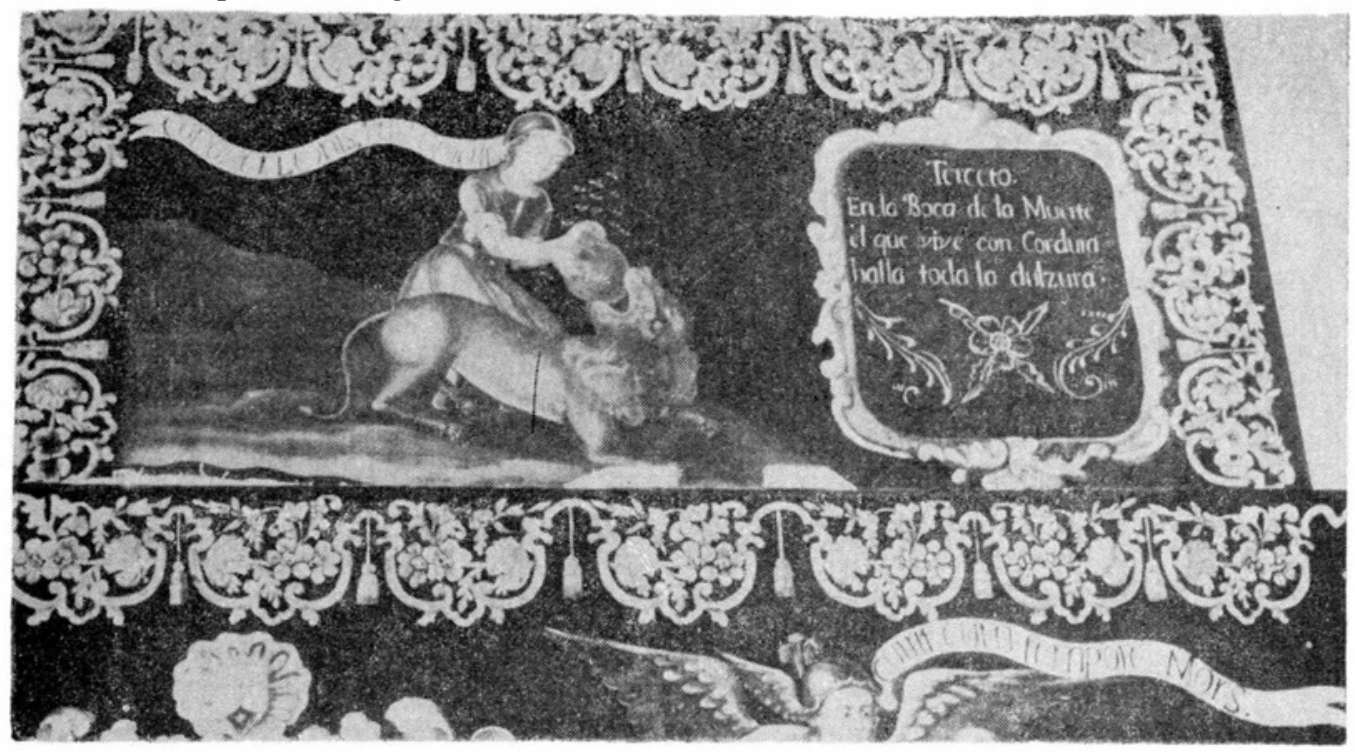

Figura 2. Sansón tomando la miel del hocico del león de Timna. Foto Rafael Rivera.

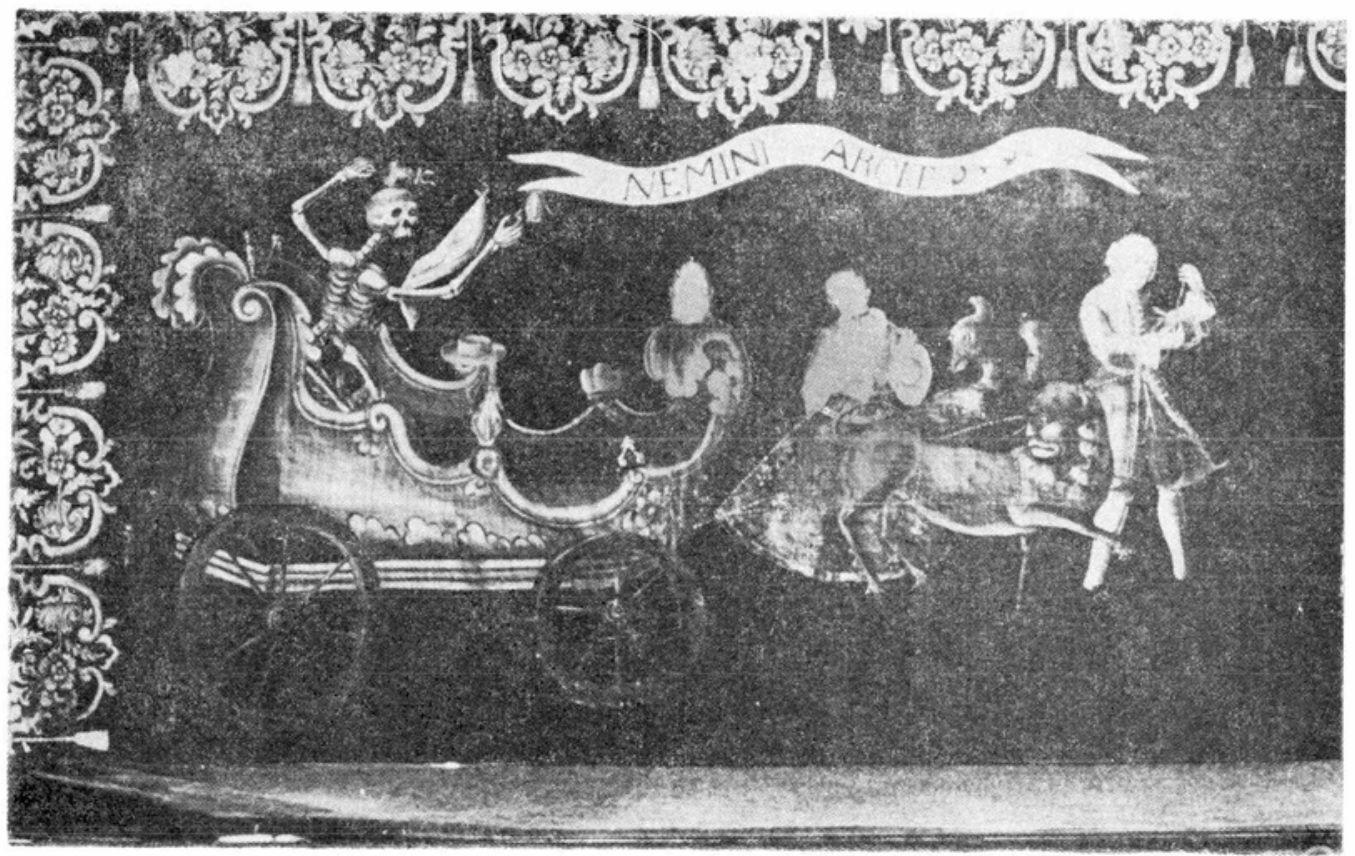

Figura 3. El Carro de la Muerte y personajes de clase adinerada. Foto: Rafael Rivera. 

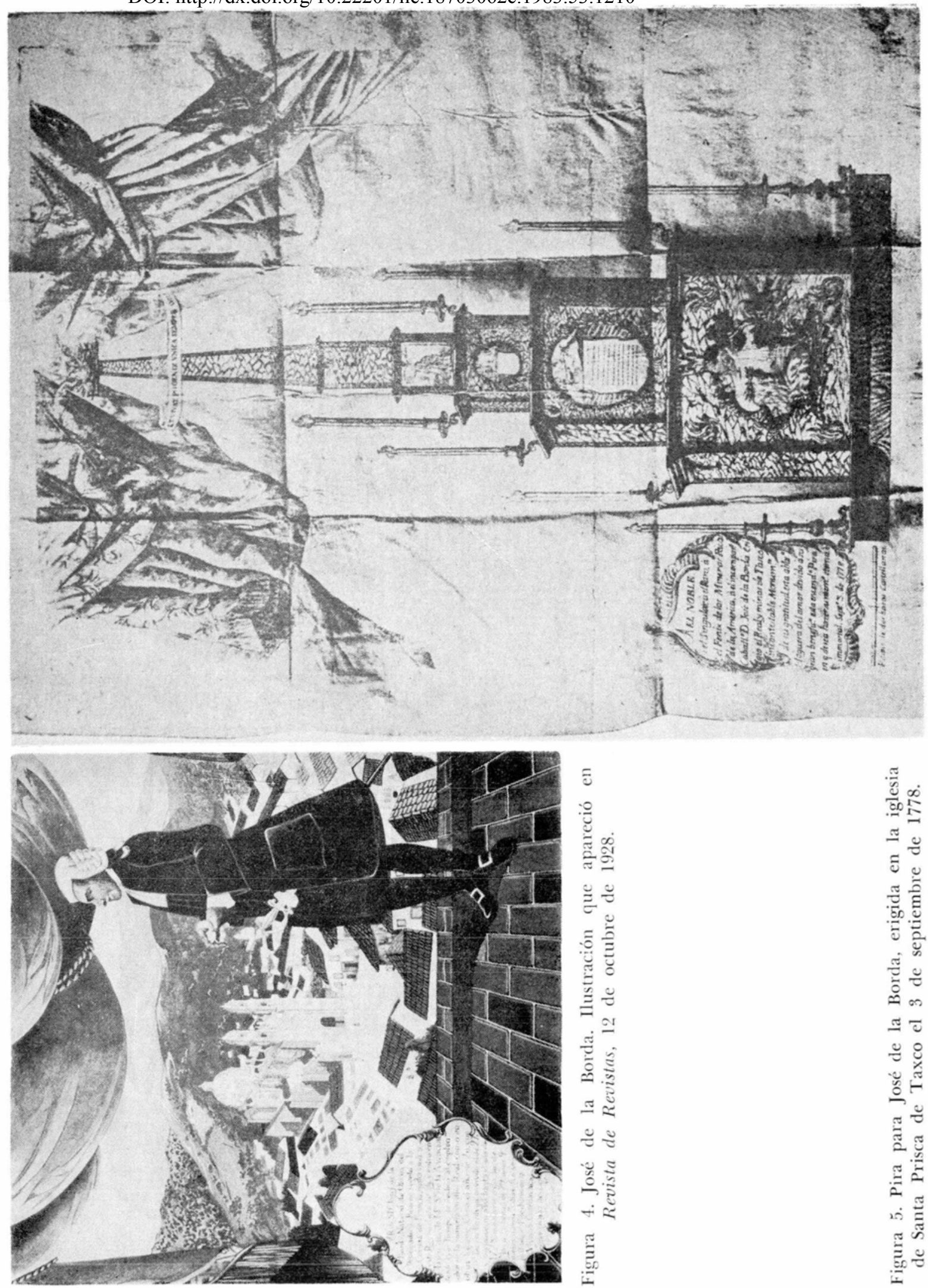
DOI: http://dx.doi.org/10.22201/iie.18703062e.1983.53.1210

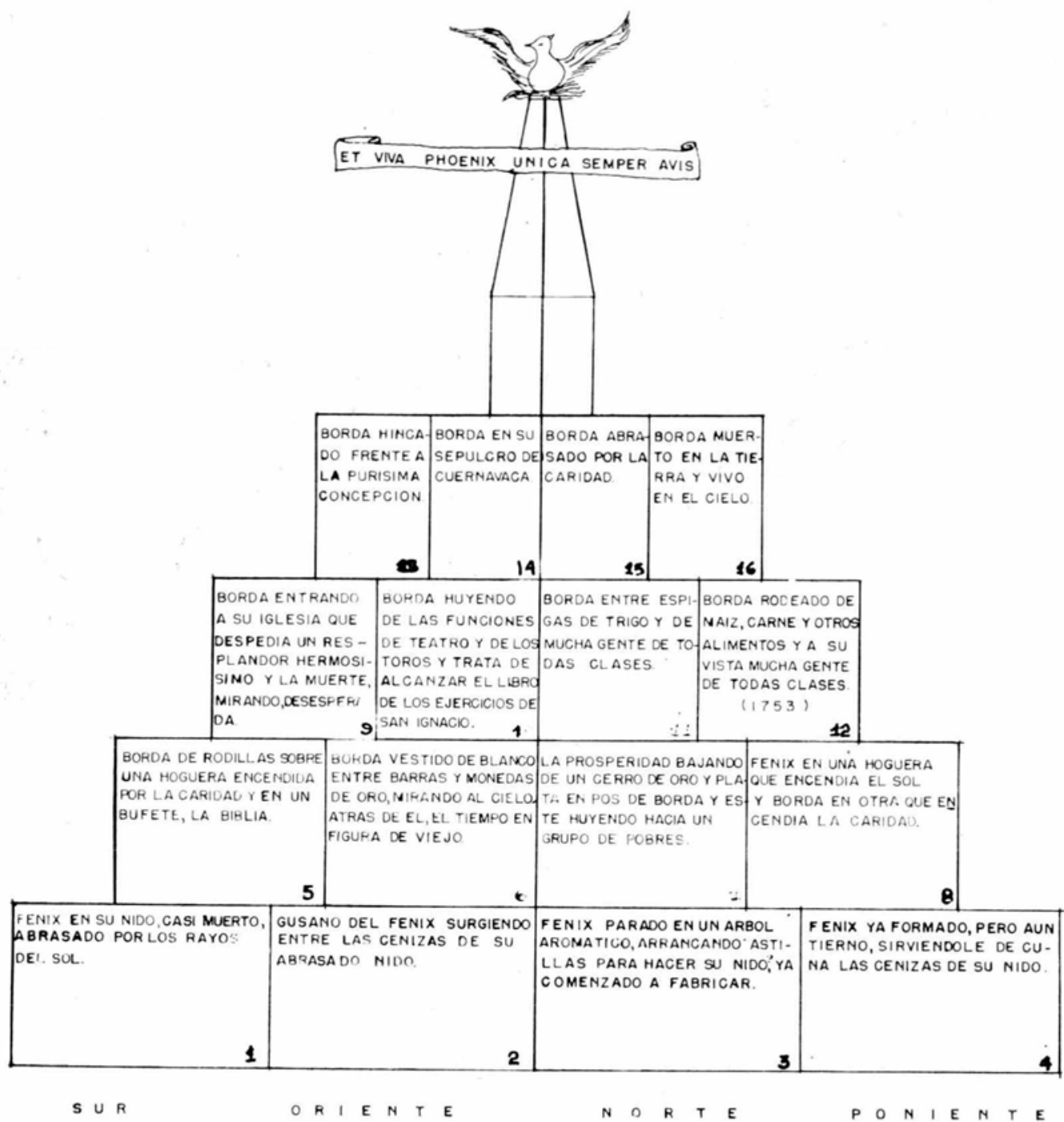

Figura 6. Esquema de la pira dedicada a José de la Borda. 